J.E. GROVES

CHAMBER OF MINES OF SOUTH AFRICA

\title{
INTRODUCTION
}

In South Africa the view has been often expressed, and was repeated by Schumann (l) that, "The mine dumps of the Witwatersrand are beautiful. We think of them with nostalgia when we are away, and we return to them with joy. When told that some think them ugly, we are startled and even offended, and ponder on the thought that if our predecessors had shared this view, if they had refused to let mine dumps spoil the austere highveld horizon, then the gold mining industry would indeed have been stillborn, and none of us would have been here to express our concern about the environment." He goes on to say, "In the past, industry, in general has been guilty of many crimes against the environment, runging from pollution to unadulterated ugliness and many of these crimes have been attributed to economic necessity when in fact they arose from thoughtlessness or outright incompetence."

A genuine lack of concrete information on certain aspects of dump construction led to many of the problems. We can see that many mines were guilty through ignorance of siting their dams in the worst possible places, but today we believe that we are more knowledgeable and it is to be hoped that the present co-operation between the mining industry and Government will ensure that these practices will not continue.

As a result of increased awareness and knowledge concerning the problems, Schumann (1) was able to congratulate the industry on being, "well ahead of the times in town planning", referring specifically to the planning of Welkom, a mining town in the Orange Free State, which included, "a scheme for planting up the surrounding and intervening space between mine workings over an area of about $40 \mathrm{~km}^{2} \ldots$ Subsequently, other completely new mine townships such as Stilfontein and Evander have provided equally attractive environments for employees." 


\section{PRESENT RECLAMATION}

The early efforts to minimise pollution from mine dumps in the Witwatersrand area were really the story of air pollution control. Under the terms of the Atmospheric Pollution Prevention Act of 1965, dust from mine dumps has only to create a nuisance to necessitate the owners of the dump taking measures to prevent pollution, and the discretion as to what constitutes a 'nuisance' rests with the Chief Air Pollution Control officer ${ }^{(2)}$.

As a result of the study undertaken by the Chamber of Mines and the C.S.I.R., which began in 1953, on structural stability of slimes dams, it was agreed that the most satisfactory method of stabilising the surfaces of slimes dams would be to establish vegetation on them $(2,3)$, and since 1961 many of the Reef's mine dumps have been vegetated. According to Clausen (3), more than $22 \mathrm{~km}^{2}$, of the total $72 \mathrm{~km}^{2}$, have been rehabilitated. Resulting from this many Government, Municipal and private development schemes, involving housing, factories and recreational areas, have been made possible, now "protected from the wind by green hills" ${ }^{(4)}$.

Schumann ${ }^{(1)}$ commented on the results of this vegetating programme by saying, "No quantitative assessments of dust abatement have been made, but the dramatic improvements achieved can be readily confirmed by householders and factory owners alike in the Southern Suburbs of Johannesburg."

Quantitative evaluation of the effects of the rehabilitation of particularly slimes dam surfaces on water pollution are already emerging. Thus, for example in the Geduld Dam near Springs, the sulphate concentration, an indicator of pollution from mine dumps, in the Geduld Dam discharge is now less than 200 parts per million, whereas prior to 1970 it had been in the 2000 to 3000 parts per million range. Above the Geduld Dam, between that and the Benoni Dam which is not polluted by mine effluent, is a catchment area of $10 \mathrm{~km}^{2}$, of slime dam and sand dump surfaces, and $10 \mathrm{~km}$ of slime silt deposited on the valley floors 
draining into the Geduld Dam ${ }^{(1,3)}$. Much work has been done in the way of vegetating the dumps in this catchment, and the figures point to a marked decrease in pollution.

In any reclamation undertaking of the size found in South Africa a compromise has to be arrived at between those species of plants which are available in large enough quantities and those which may be deemed to be completely tolerant and adapted to the conditions found on the tailings dams, bearing in mind that these dams have variable properties and different aspects.

From experience, and within the bounds of this compromise, a list of plant species has been arrived at for use on the majority of sites, but it is usually difficult to predict with any certainty those species which may predominate, owing to the variable climatic and edaphic conditions experienced on any site. Notwithstanding the above, pyrite oxidation generally presents the greatest of many problems encountered in gold mine tailings rehabilitation, as the sulphuric acid thus produced lowers the $\mathrm{pH}$ of the material sufficiently to bring into solution phytotoxic elements such as aluminium, iron and manganese. (Contrary to general opinion, the presence of cyanide in slimes dams is not a problem as within two months of the slimes being deposited, any remaining cyanide used in the gold extraction process is chemically broken down $\left.{ }^{(4)}\right)$. As a result of this phytotoxicity problem the permanence of the vegetation can be questioned, but in all cases animal, bird and insect life moves into a reclaimed area as soon as vegetation begins to grow ${ }^{(4)}$, which is encouraging at least, and points towards successful establishment.

From 1958 to the end of June, 1972, the amount of money spent on dust suppression (and prevention of run-off) from mine dumps by the mining industry was over R6 $000000^{(2)}$. By December 1973 a further Rl 210745 had been expended in reclamation work by the Chamber of Mines Vegetation Unit alone. 
For the seven years from 1966 to 1973, on average the Vegetation Unit had rehabilitated 413,1 hectares per annum of slimes dams and sand dump surfaces at a cost per hectare of R800 - Rl 200 for slimes dams tops, R2 000 - R2 500 for slopes, and R1 200 - R1 600 for sand dumps entire.

These figures illustrate the increasing difficulty of the working sites attempted, and the inflation in the costs of materials and labour when compared with James and Mrost's 1965 report ${ }^{(5)}$.

\section{FUTURE}

Taking the average rate of slimes dam and sand dump reclamation over the above seven year period, and assuming that no new dams will be constructed, the work of the Chamber of Mines Vegetation Unit will be completed by 1983, at a cost in excess of R13 000000 . This date for completion assumes that there will be no failures, no fires (an unfortunate, very damaging, hazard ever present during the winter months, necessitating extensive repair work), and no reworking of dumps already grassed.

None of these assumptions are at all realistic; however, certain recommendations have been made which should make the grassing of new slimes dams easier than in the present or past.

These recommendations underline the new awareness of aesthetics apparent within the mining industry. Clausen ${ }^{(3)}$ was able to demonstrate that a slimes dam constructed in accordance with aestetic considerations could also cost less to construct and finally rehabilitate. A combination of good economics, and aesthetics, within the framework of the present climate of world opinion, represents an exceedingly persuasive argument for vigorous future planning concerning the relationship between mining and reclamation, and where pertinent, between these and road building, township development and the provision of formal and informal recreational facilities.

Several of the problems associated with the rehabilitation of mine dumps 
are well known but four of these which are receiving constant attention by the Chamber of Mines Vegetation Unit are:

a) Fertiliser levels necessary for plant establishment and maintenance.

b) In common with overseas practices ${ }^{(6)}$ the use of chemical stabilising agents have been investigated (since 1911), but to date no single agent has been found to be entirely satisfactory, in most cases owing to their lack of physical strength or permanence in situ.

c) The effect of leaching on pyrite and acidity levels, and the Available Water Holding Capacity of slimes particularly.

The physical nature (texture and porosity) of the tailings ensures that the infiltration of water is very slow, relative to soils, and although slimes dams rarely "dry-out" as such, only a small proportion of the moisture present may be available to plants, and physiological drought may be further accelerated by the salinity and high osmotic pressure present in some slimes dam "soil solutions".

d) The ecology of mine dumps already reclaimed is being, and will be, investigated. The approach to reclamation in South Africa has been to ameliorate the tailings and to introduce vegetation of the types easily available and demonstrably tolerant to climatic conditions.

In Britain, Bradshaw ${ }^{(7)}$ and Smith and Bradshaw ${ }^{(8)}$, and in Rhodesia, Hill (9), have adopted the approach whereby subjects which are tolerant to the specific environment both climatic and edaphic are utilised. This method will be investigated; however the edaphic environment found in gold mine tailings is subject to continual change, and thereby presents greater problems than are encountered either in Britain or Rhodesia. Also the two approaches appear to eventually produce similar results, and the 
South African method of reclamation may inherently involve fewer field scale practical problems.

\section{$\underline{\text { CONCLUSION }}$}

Atmore in $1972^{(10)}$ made these most relevant remarks, "What is important is that today, all over the world, man has come to realise that the pursuit of material prosperity ought not to be achieved at the cost of sacrificing to any considerable degree the other qualities of life. How society is to value the degree of impairment, in relation to the degree of economic advance, is really what the argument is all about. It is surely not beyond our ingenuity to learn how to weigh the various factors objectively and find solutions that are broadly acceptable to the society concerned."

Also, "The very nature of its business gives the mining industry a special and important place in the fight against pollution. Everything it does directly affects the environment in one form or another, and the industry has not been unmindful of its responsibilities and obligations in conserving, and where feasible, restoring natural amenities. However, it could do more..."

McMahon in his review ${ }^{(6)}$ was able to conclude, "Extensive research programmes....throughout the world.... have shown that the most effective means of treating mineral wastes, to combat air and water pollution and to create an aesthetically pleasing result, is the revegetation of waste areas.

Cost has emerged as a major factor in determining the feasibility of any treatment method employed... increasing attention is now being given to improving efficiency of operation in order to lower the per acre cost of treatment. Mechanisation will play an important role in this trend.

South Africa, Canada and the U.S.A. have become the leading countries in the development of revegetation techniques." 


\section{ACKNOWLEDGEMENTS}

It has been impossible to improve on the statements as presented in the papers from which I have quoted, and I wish to thank the Chamber of Mines for allowing me access to such information as is available, and for permission to present it.

\section{REFERENCES}

1. SCHUMANN, A.W.S., 1974 Mining Survey Number 74 pp 17-24.

2. GRANGE, G.H., 1973 J. S.Afr. Inst. Min. Met. $\underline{74}$ (2) pp 67-73.

3. Clausen, H.T., 1973 J. S.Afr. Inst. Min. Met. $\underline{74}$ (5) pp 178-183.

4. COOK, W.H., 1971 The Clean Air Journal 1 (l) pp 21-6.

5. JAMES, A.L., and MROST, M.J., 1965 J. S.Afr. Inst. Min. Met. 65 $\mathrm{p} 488$.

6. McMAHON, R.G.P., 1971 Bull. Aust. Mineral Dev. Labs. No. 12 pp 81-100.

7. BRADSHAW, A.D., 1952 Nature 169 p 108.

8. SMITH, R.A.H., and BRADSHAW, A.D., 1972 Trans. Inst. Min. Met. 81 pp A 230- A 237.

9. HILL, J.R.C., 1973 J. S.Afr. Inst. Min. Met. $\underline{74}$ (5) pp 197-208.

10. ATMORE, M.G., 1972 Optima $\underline{22}$ (3) pp 14l-147. 